\title{
A "Educação Rural no México" como referência para o Brasil
}

\author{
The "Rural Education in Mexico" as a reference for Brazil
}

Rosa Fátima de Souza

Universidade Estadual Paulista "Júlio de Mesquita Filho" | Araraquara Universidade Estadual Paulista | Campus Marília

\section{Resumo}

Nas décadas de 1940 e 1950 do século XX, o governo brasileiro implementou várias políticas voltadas para o desenvolvimento da educação rural, adotando orientações inovadoras experimentadas em outros países da lbero América. Este texto compreende um estudo sobre circulação e apropriação de modelos educacionais buscando apreender as implicações das operações comparativas interrogando os processos nacionais em suas inter-relações com fenômenos mais amplos de internacionalização e globalização. $\bigcirc$ estudo utiliza como fonte de análise o documento intitulado Educação Rural no México, elaborado por Manoel Bergstrom Lourenço Filho, em 1951 e posteriormente publicado na Revista Brasileira de Estudos Pedagógicos em 1952. O texło põe em questão a construção narrativa desse relatório e as operações de comparação que Lourenço Filho empreendeu apresentando a educação mexicana como modelar.

Palavras-chave: Educação rural. História da educação rural. Circulação de modelos educacionais.

\section{Abstract}

In the 1940's and 1950's the Brazilian government implemented various policies towards the development of rural education adopting innovative orientations experienced in other iberoamerican countries. This article covers a study on the circulation and appropriation of education models seeking to apprehend the implications of the comparative operations by questioning the national processes in their interrelationship with much more ample phenomena of internationalization and globalization. The article uses as source of analysis the document entitled "Rural Education in Mexico" elaborated by Manoel Bergstrom Lourenço Filho, in 1951, and later published in a Brazilian Magazine of Pedagogical Studies, in 1952. The article discusses the narrative construction of this report and the comparing operations which Lourenço Filho has undertook presenting the Mexican education as a model.

Keywords: Rural education. History of Rural Education. Circulation of education models. 
Iniciada sob feliz inspiração de uma pedagogia de caráter social, a educação rural mexicana, tende, enfim, a desenvolver, de modo mais nítido, um vasto plano de 'educação fundamental', em que a ação da escola, e de outros processos de difusão cultural e a do serviço social de grupo, venham a solidarizar-se com os planos de governo, no sentido do progresso material e moral de cada região, admitido sempre, no entanto, o respeito aos princípios democráticos. (LOURENCCO FILHO, 1951 ).

Em 1951, o educador brasileiro Manoel Bergstrom Lourenço Filho realizou uma viagem de estudos ao México a pedido do Ministro da Educação e Saúde, Simões Filho, com o objetivo de conhecer e avaliar o movimento de educação rural em desenvolvimento naquele país. Como resultado da visita, Lourenço Filho apresentou um relatório circunstanciado intitulado Educação Rural no México. (LOURENÇO FILHO, 1951). Esse relatório foi divulgado no Brasil para os órgãos da administração do ensino dos vários estados da federação brasileira, foi publicado em periódico educacional de circulação nacional (LOURENÇO FILHO, 1952) e, em 1961, compôs um dos capítulos do livro Educação Comparada, de autoria do educador. (LOURENÇO FILHO, 19611 .

A visita de Lourenço Filho ao México fazia parte das iniciativas que vinham sendo empreendidas pelo governo brasileiro em prol da educação rural considerada, na época, um dos maiores problemas educacionais do país. Essas iniciativas estavam articuladas com as propostas em circulação em âmbito internacional, especialmente as orientações da Organização das Nações Unidas para a Educação, a Ciência e a Cultura (UNESCO), a Organização dos Estados Americanos (OEA) e das agências norte-americanas, mediante acordos assinados entre Brasil e Estados Unidos.

Diante das experiências em curso em vários países da América Latina e da América do Norte, despontava-se a educação mexicana pelo pioneirismo na implantação de um amplo programa sociocultural de educação de base envolvendo as comunidades rurais e indígenas. $\bigcirc$ intercâmbio com os administradores da Educação mexicanos possibilitou a Lourenço Filho fundamentar as bases da Campanha Nacional de Educação Rural (CNER) que vigorou no Brasil no período de 1952 a 1963.

relatório intitulado Educação Rural no México, elaborado por Lourenço Filho, no final de 1951, constituiu-se em um detalhado documento 
sobre princípios, concepções, estrutura e organização da educação rural mexicana. A análise desse relatório é importante para se compreender melhor os referenciais estrangeiros que informaram as políticas e iniciativas nacionais para a educação rural, em meados do século XX, especialmente a experiência das Missões Culturais e a concepção de educação de base e de educação fundamental.

Trata-se, portanto, de um estudo sobre circulação e apropriação de modelos educacionais que permite apreender as implicações das operações comparativas e o intrincado processo de reforma e inovação educacionais interrogando os processos nacionais em suas inter-relações com fenômenos mais amplos de internacionalização e globalização'.

estudo fundamenta-se na literatura sobre educação comparada e internacionalização da educação, especialmente em autores como Schriewer (2000, 2002), Nóvoa e Yariv-Mashal (2003) e Nóvoa (1998, 2009) que têm se dedicado à compreensão do problema da alteridade cultural e dos processos de transferência de referenciais educacionais estrangeiros.

\section{O problema da educação rural no Brasil}

Nos anos 1930 do século XX, mais de 70\% da população brasileira ainda residia na zona rural. Apesar dessa concentração populacional no campo, as políiticas educacionais continuavam priorizando as zonas urbanas.

O problema da educação rural esteve em debate na sociedade brasileira desde o século XIX, mas somente no final dos anos 1940 do século XX foram empreendidas políiticas efetivas do governo federal para a disseminação do ensino primário no campo. Durante a chamada Era Vargas (1930-1945) intensificou-se no país o debate sobre a educação rural. A preocupação com a educação rural esteve associada nesse momento ao "projeto autoritário" do governo do Presidente Getúlio Dornelles Vargas de modernização da sociedade brasileira. A educação rural foi vista como um meio de contenção do fluxo migratório, de saneamento do interior e de formação técnica. (BARREIRO, 1997).

A questão da educação rural foi sobejamente discutida na Conferência Nacional de Educação, realizada no Rio de Janeiro em 1941 e no Congresso Brasileiro de Educação, promovido pela Associação Brasileira de Educação, 
em 1942, em Goiânia, recém-criada capital do estado de Goiás, cujo tema geral foi A educação primária fundamental. (ÁVILA, 2013).

Durante o Estado Novo foram implementadas algumas políticas nacionais para o desenvolvimento do ensino primário rural. Em 1942 foi criado o Fundo Nacional de Ensino Primário (Decreto n 4.958, de 14 de novembro) pelo qual o governo federal estabeleceu planos de cooperação financeira e técnica para com os estados da federação para a ampliação e melhoria do sistema escolar do país. Este Fundo, juntamente com o Convênio Nacional do Ensino Primário sob a supervisão do Instituto Nacional de Estudos Pedagógicos (INEP) possibilitou o investimento na construção de escolas rurais em várias regiões do país.

Em realidade, a melhoria das condições de vida das populações do meio rural foi vista como questão estratégica para o desenvolvimento do Brasil. Estado brasileiro valeu-se então da conjuntura internacional do pós-Segunda Guerra Mundial para articular políticas específicas para o desenvolvimento do campo. Vários acordos foram celebrados com os Estados Unidos que buscaram conter o avanço do comunismo investindo no desenvolvimento dos países da América Latina. A propósito esclarece Iraíde Barreiro:

Por meio da $\mathrm{ONU}$, os Estados Unidos passaram a trabalhar com o objetivo de garantir a 'ordem social' e preservar o 'mundo livre', lutando para manter um número maior de países sob o seu domínio político, econômico e ideológico. Acreditavam que, na luta ideológica, os povos famintos assimilam melhor a propaganda comunista, quando comparados às nações prósperas. Esse fato levou o governo americano a iniciar, após a Segunda Guerra Mundial, um extenso programa de assistência técnica aos países pobres, especialmente aqueles situados na América Latina. (BARREIRO, 2006, p. 124).

Em 1945, o Brasil firmou Acordo sobre a Educação Rural entre o Ministério da Agricultura e a Inter American Educational Foundation, Inc. resultando na criação da Comissão Brasileira Americana de Educação das populações Rurais (CBAR). Segundo Barreiro (2006), esse Acordo sugeriu a adoção de Missões Rurais para o campo e o uso da estratégia de Desenvolvimento de Comunidade institucionalizado pela Organização das Nações Unidas (ONU) com a deflagração da Guerra Fria. Portanto, a política 
governamental já vinha se utilizando do referencial externo para legitimar as iniciativas políticas nacionais na área da educação rural.

Alguns educadores, como Lourenço Filho, tiveram um papel importante no intercâmbio com outros países promovendo a circulação de modelos e participando do processo de internacionalização da educação rural. A trajetória desse intelectual revela uma longa experiência de trabalho na esfera da administração federal do ensino.

Em 1937, foi nomeado membro do Conselho Nacional de Educação e passou a exercer o cargo de Diretor-Geral do Departamento Nacional de Educação, do Ministério da Educação e Saúde. Nesse período trabalhou na implantação do Instituto Nacional de Estudos Pedagógicos (INEP), órgão vinculado ao Ministério da Educação, o qual dirigiu até 1946. Ao deixar a direção do INEP, ocupou, pela segunda vez, o cargo de Diretor-Geral do Departamento Nacional de Educação. Nessa segunda gestão, organizou e dirigiu a Campanha Nacional de Educação de Adultos. (cf. FÁVERO; BRITO, 2002; MONARCHA, 2010).

Em 1949, Lourenço Filho participou da organização do Seminário Interamericano de Alfabetização e Educação de Adultos, promovido pelo governo brasileiro, a União Pan-Americana e a UNESCO, realizado em Petrópolis, estado do Rio de Janeiro. Nesse seminário os participantes debateram diversos sistemas educacionais nas Américas, especialmente algumas importantes experiências de educação no meio rural. Nesse seminário, Lourenço Filho recebeu o título de Maestro de las Americas.

Segundo consta no documento elaborado pelo Serviço de Informação Agrícola, foi a partir desse seminário que José Irineu Cabral, Diretor do Serviço de Informação Agrícola e Lourenço Filho, então Diretor-Geral do Departamento Nacional de Educação, propuseram a organização de uma experiência de educação de base no Brasil visando à recuperação e ao desenvolvimento de comunidades rurais. Essa proposição resultou na experiência de Itaperuna - Rio de Janeiro, uma missão rural de educação de adultos instituída com a finalidade de

[...] obter o maior número possível de elementos que permitissem indicar, no plano nacional, diretrizes técnicas de processos educativos e assistenciais visando à melhoria das condições de vida econômica e social do meio rural. (MISSÕES RURAIS DE EDUCAÇÃO..., 1952, p. 10). 
Essa experiência de Itaperuna constituiu-se num dos primeiros passos para a instituição em 1952 da Campanha Nacional de Educação Rural (CNER) fundamentada nos princípios e técnicas do Desenvolvimento de Comunidade e nas missões rurais. A viagem de estudos de Lourenço Filho ao México pode ser compreendida no contexto dessas iniciativas do governo brasileiro em torno da educação rural.

Em realidade, Lourenço Filho já havia visitado o México anteriormente e participado em 1947 da III Conferência Geral da UNESCO. O retorno em 1951 tinha uma finalidade política bem definida. Tratava-se de examinar com profundidade as práticas de educação rural levadas a termo no México, aprender bem as lições para implementar políticas semelhantes no Brasil.

Ainda no ano de 1951, Lourenço Filho deixou a direção do Departamento Nacional de Educação sendo nomeado Presidente da Comissão Executiva do Centro de Formação para Educação Fundamental na América Latina e representou o Brasil no Conselho Cultural Interamericano, ambos com sede no México. As múltiplas relações de intercâmbio e diálogo estabelecidas por esse educador brasileiro com educadores, intelectuais e políticos mexi66 canos, são elementos importantes para se

Como assinalam Mignot e Gondra (2007), as viagens de educadores consistem em um tipo de estratégia de aproximação com os modelos pedagógicos de outros países. No caso de Lourenço Filho, sobressai o interesse intelectual pela educação comparada pronunciado anos antes na viagem de estudos realizada por ele nos Estados Unidos. (WARDE, 2003).

O livro que ele publicou em 1961, intitulado Educação Comparada, pode ser visto como um manual destinado aos estudantes de pedagogia e dos cursos de formação de professores. Ele reúne vários estudos comparados realizados pelo autor ao longo do tempo. Na primeira parte do volume, Lourenço Filho discute "[...] a conceituação geral de educação comparada, a origem e desenvolvimento de seus estudos, suas fontes, recursos e métodos." (LOURENÇO FILHO, 1961, p. 9).

Na segunda parte, apresenta súmulas referentes à organização e administração educacional em dez países - cinco da Europa (Inglaterra, França, República Federal Alemã, Itália, U.R.S.S.), três da América (Estados Unidos, México, Argentina) e dois da Ásia (Japão, Índia). 
A terceira parte refere-se a um ensaio sobre programas de ensino primário em todos os países da América Latina, preparado pelo autor, a pedido da UNESCO, como documento de trabalho da II Conferência Interamericana de Ministros e Diretores de Educação, reunida em Lima em 1956. O último capítulo compreende o relatório sobre a educação rural no México produzido em 1951.

Para Lourenço Filho comparar consistia em um recurso de conhecimento necessário aos educadores para o esclarecimento de problemas teóricos e práticos relacionados à educação. A educação comparada tinha a finalidade de aguçar a capacidade de observação e de compreensão do trabalho educativo. Dado que os sistemas de ensino refletiam as condições integrais de vida de cada povo, pela análise dessas condições e influências na ação educativa, os teoristas podiam formular hipóteses válidas confrontando doutrinas e teorias existentes com modelos práticos de organização escolar. Como afirmava o autor: "O que se colhe nos estudos comparativos é um conjunto de informações que conduzem a hipóteses operativas, por maior elucidação das condições do processo educacional." (LOURENÇO FILHO, 1961, p. 17).

O objetivo da comparação é claro; trata-se por um lado, da busca de formulação de leis gerais para a constituição de uma ciência da educação, e, por outro lado, de oferecer elementos para compreensão do sistema educacional nacional pelo contraste.

O texto de Lourenço Filho sobre a educação rural no México alinha-se, portanto, a um tipo secular de estudos comparados que resultam de relatórios de viagens. Sobre essa tendência de produção da educação comparada, Nóvoa (2009) assinala que a descrição dos sistemas educativos estrangeiros, de sentido prescritivo e factual, representa uma das primeiras tradições do campo.

Buscando identificar as motivações socioculturais, econômicas e políticas que explicam as formas de organização do ensino adotado em determinado país, tais estudos, ao reunirem informações detalhadas sobre aspectos normativos e de funcionamento dos sistemas de ensino destacando a organização administrativa e pedagógica, ofereciam aos administradores da educação um manancial de elementos para contrastes e reflexões. Enfim, a finalidade desses relatórios de observação e descrição dos sistemas educacionais estrangeiros era contribuir para a melhoria do sistema de ensino nacional. 
Em relação à educação rural no Brasil, a contribuição do relatório de Lourenço Filho sobre a educação rural mexicana foi destacada na Revista da Campanha Nacional de Educação Rural, publicada em 1959, no número dedicado ao histórico da Campanha:

É ainda, da autoria do citado diretor do DNE, um magnífico Relatório de 93 páginas, intitulado 'A Educação Rural no México', em que o autor, tendo visitado aquêle país por determinação do Ministro da Educação, em 1951, dá conta de suas observações quanto às origens do movimento de ensino rural mexicano e do desenvolvimento de um sistema de escolas e de 'missões', resultados obtidos, tendências e perspectivas de então.

Esses elementos de estudo sobre experiência alienígena, somados aos resultados das observações quanto aos aspectos positivos e negativos do trabalho que se vinha fazendo em Itaperuna, determinaram à nova gestão da Diretoria do DNE, naquele exercício, estudos e diretrizes com interesses peculiaríssimos ao Brasil. (A CAMPANHA NACIONAL..., 1959, p. 14-151.

Que aspectos da educação mexicana atraíram a atenção de 68 Lourenço Filho e foram divulgados em seu relatório? Como as transformações educacionais ocorridas no México foram retratadas pelo educador? Como ele caracterizou as missões culturais e o programa de educação de base? Essas questões são importantes para a reflexão sobre o diálogo estabelecido pelos educadores brasileiros com os modelos internacionais no âmbito da educação rural.

\section{A educação rural no México no olhar de Lourenço Filho}

Mais que um relatório de atividades e observações constatadas na visita realizada ao México, Lourenço Filho elaborou um minucioso estudo sobre a educação rural mexicana. É provável que ao adotar essa estratégia discursiva, o educador buscasse oferecer aos leitores brasileiros - políticos, administradores do ensino, educadores e para a sociedade civil, argumentos válidos para justificar a implementação da Campanha Nacional de Educação Rural que estava sendo planejada pelo Ministério da Educação e Saúde, cujo 
ensaio de experimentação começara a ocorrer em Itaperuma, no mesmo ano de sua viagem.

De acordo com o autor, o relatório fora elaborado com o objetivo de oferecer "visão sucinta, mas sempre suficientemente documentada, desse movimento, tentando ademais explicar-the as condições de origem e de evolução." autor tratou de justificar a relevância do movimento de educação rural estudado. No prefácio assinalou o caráter inovador da experiência em curso no México que vinha se processando desde 1921 : "[...] um movimento de educação rural, que é apontado como das maiores realizações de pedagogia social já tentadas em qualquer parte do mundo." (LOURENÇO FILHO, 1951 , p. V).

Do ponto de vista da política educacional, o educador considerava o movimento mexicano rico em sugestões. Ele dizia que as três fases históricas identificadas no movimento correspondiam às três tendências da política geral: na primeira fase, entre 1921 e 1934, caracterizava-se pela ampla visão social da obra educativa, marcada pela ideia de pronta assimilação cultural dos indígenas. A segunda fase, iniciada em 1935 com a reforma constitucional, atribuiu um caráter socialista à educação do país. A partir de 1941, o sentido da educação foi novamente alterado passando a prevalecer o pressuposto, segundo o qual, a educação deveria servir à integração do espírito nacional assegurando os ideais democráticos e a consciência da solidariedade internacional. (LOURENÇO FILHO, 1951, p. VI).

No México, Lourenço Filho visitou escolas, examinou documentos oficiais e manteve contato com autoridades educacionais. Como observador experiente na administração do ensino público, avaliou o movimento educacional com arguto olhar comparatista. Não era a primeira vez que o educador brasileiro exercitava a comparação de sistemas educacionais. Em 1935, visitou os Estados Unidos em missão de trabalho encomendada pela DiretoriaGeral da Instrução Pública do Distrito Federal para examinar os padrões norte-americanos de educação. (WARDE, 2003).

Pela sua relevância para os estudos de educação comparada, na opinião do educador, a educação rural no México sobressaía por duas razões: em primeiro lugar estava a originalidade do movimento em curso naquele país. Em segundo lugar, destacavam-se os processos de ação técnica e de ação pedagógica, especialmente o "[...] serviço social de grupo" mediante 
a criação de instituições originais como as chamadas "missões culturais" e as "brigadas civilizadoras."2

Oexemplo mexicano oferecia interesse também pelo ponto de vista técnico, isto é, pela experiência da concepção de educação fundamental ou educação de base, elaborada pela UNESCO e recomendada para os países da América Latina. Além disso, o movimento era rico em sugestões em relação à política educacional.

Lourenço Filho dividiu o relatório em 4 secções: 1) Origens do movimento do ensino rural, 2) Organização e desenvolvimento de um sistema, 3) Situação atual da educação rural, 4) Tendências, resultados gerais e perspectivas.

Na primeira parte do relatório, o autor discorreu sobre a revolução mexicana de 1910 e a reforma agrária ocorrida nesse país. Ressaltou como o movimento enfatizou o lema "tierra y escuela" "único na história das revoluções de todo o mundo." Afirmou também que alguns líderes mexicanos acariciavam a ideia de "tentar uma profunda reforma dos costumes através da escola" e que o movimento revolucionário buscou a afirmação de uma pedagogia social.

A atuação de José Vasconcelos foi ressaltada pela criação do Departamento de Educação e Cultura Indígena e pela implementação das missões culturais. Para Lourenço Filho, o ensino rural no México não partira de uma teoria pedagógica perfeitamente elaborada e sim de uma experimentação sob a forma de um grande ensaio de reforma social. Reconhecia nessas ideias a influência de John Dewey e dizia que muitas concepções em vigor naquele momento haviam norteado mais tarde o conceito de "educação fundamental" ou "educação de base" no sentido empregado pela UNESCO. 
Na segunda parte do relatório, o autor referiu-se ao período de subida de Lazaro Cárdenas ao poder, quando foram modificados os preceitos constitucionais referentes à educação. Segundo Lourenço Filho, o Ministério da Educação mexicano teve que enfrentar o capital problema da formação e orientação dos mestres. A solução, foi o aproveitamento de elementos locais, escolhidos em cada comunidade onde pudesse abrir uma "casa del Pueblo".

Na sequência discorreu com detalhes sobre a trajetória das missões culturais desde a primeira implantação no México, cuja relevância assinalou: "Representam, por outro lado, contribuição original da pedagogia mexicana à pedagogia universal, como processo de 'educação fundamental' agora aceito por outros diversos países, que defrontam problemas de cultura similares." (LOURENÇO FILHO, 1951 , p. 26). Para confirmar suas impressões apresentou quadros da expansão das escolas, das missões e dos professores no ensino rural mexicano.

No capítulo terceiro, o mais longo de todos, Lourenço Filho fez uma descrição minuciosa da ação do governo federal mexicano em relação à educação popular, por meio das missões culturais e de outros processos de extensão cultural, dando ênfase às missões culturais. Iniciou o capítulo afirmando:

Desenvolveu-se a educação rural no México, por mais de vinte anos, essencialmente por um sistema de escolas primárias federais, cujo trabalho de sentido social, era apoiado por "missões culturais", e, em determinadas zonas, também por serviços de extensão educativa entregue a certo número de escolas normais rurais e de escolas práticas de agricultura. Essa fase correspondeu, no plano da política geral, como vimos, à de afirmação e execução da reforma agrária. (LOURENÇO FILHO, 1951, p. 33).

Porém, na opinião do autor, no governo de Cárdenas e Ávila Camacho (1940 - 1946), ocorrera uma mudança na orientação política da educação face aos novos problemas de ordem econômico-social.

Reorganizaram-se os serviços das 'missões', que passaram a terem várias modalidades, entre as quais as de 'missões para bairros operários', nas cidades; ampliaram-se os serviços de extensão cultural, pelo teatro popular, bibliotecas e publicações, rádio e cinema, e, como laço geral, entre todos esses serviços, organizou-se, em 1944, a Campanha Nacional contra o Analfabetismo. (LOURENÇO FILHO, 1951, p. 33). 
Na sequência do texto, passou a tratar das normas de organização e funcionamento da escola rural. Discorre sobre o sistema de escolas primárias federais (a administração geral), os diretores federais, os serviços de inspeção escolar, o corpo técnico e consultivo da Direção Geral, a direção das escolas rurais, a organização do ensino e os programas, os anexos escolares (oficinas de trabalhos manuais, teatros abertos, etc.), a parcela escolar (lote reservado às atividades de horticultura, ensaio de cultivo e pequena plantação) e a ação social.

Depois o autor deteve-se no exame do sistema das Missões Culturais, que, segundo ele, "[...] apresentam-se hoje como instrumentos específicos de 'educação de adultos', ou de serviço social de grupo." "LOURENÇO FILHO, 1951 , p. 45).

Registrou detalhadamente outros aspectos das missões como o ritmo dos trabalhos, as concepções e as atividades desenvolvidas. Para explicitar ainda mais a organização das missões, transcreveu trechos da publicação intitulada Bases para la organización y conducion del trabajo de las Missiones Culturales", instruções baixadas em outubro de 1950, pela Direção Geral de alfabetização e Educação Extraescolar estabelecendo os objetivos das missões 72 e fixando normas de ação e as atribuições do pessoal.

Os trechos citados por Lourenço Filho são elucidativos das finalidades das missões rurais mexicanas com vistas a recuperar e civilizar a população camponesa.

As missões culturais são órgãos de educação extra-escolar criadas para promover, dentro de uma esfera de ação, a reabilitação e melhoramento das comunidades rurais, dos núcleos de trabalhadores de centros fabris e de mineração e dos bairros proletários das cidades; devem fundamentalmente, suscitar o desejo de obtenção de mais altos níveis de vida. (LOURENÇO FILHO, 1951, p. 49- 50).

Lourenço Filho preocupou-se também em registrar os resultados do trabalho das missões culturais. Mesmo reconhecendo a dificuldade de apontar resultados sistemáticos, afirmou ter examinado documentos e conversado com vários educadores redundando em uma avaliação positiva:

A impressão dominante, mesmo quando, com absoluta honestidade, sejam relatados casos de pequena influência, ou de difícil 
atuação entre as populações indígenas mais atrazadas, é a de que as 'missões culturais', onde estacionam, deixam sempre saldo favorável, como instrumento de estimulação social, e, sobretudo, de integração das populações marginais aos problemas da vida do país, em geral. (LOURENÇO FILHO, 1951, p. 54).

Dizia, ainda, que suas impressões eram confirmadas pelo estudo bem feito, realizado por Llyd $\mathrm{H}$. Hughes, intitulado Las Missiones Culturales Mexicanas y su programa, realizado a pedido da UNESCO em 1949 e publicado em 1951.

Lourenço Filho deu continuidade ao relatório discorrendo sobre a Campanha contra o Analfabetismo. Tratou também dos Serviços da DiretoriaGeral de assuntos Indígenas, da Diretoria-Geral do Ensino Agrícola, dos internatos de ensino primário e dos Serviços de extensão cultural. Sobre esse serviço, assinalou uma apreciação favorável. Afirmava ter examinado documentação fotográfica sobre teatro escolar aproveitando motivos folclóricos que o deixaram vivamente admirado.

Impressionaram-nos também os ensaios de teatro popular, com crianças e jovens, a que assistimos, à noite, em várias escolas do interior do estado de Michoacán. Numa delas, o ensaio estava sendo realizado à luz de duas velas, sem que isso fizesse esmorecer o entusiasmo dos mestres, alunos e assistentes, em que se via numerosas pessoas das famílias dos alunos. (LOURENÇO FILHO, 1951 , p. 65).

Mencionou ainda o serviço de rádio, teatro popular, música, dança, cinema educativo e as publicações populares. Por último, concluiu o capítulo reconhecendo que as iniciativas educacionais mexicanas vinham tratando a educação rural como sistema de 'educação fundamental':

Os dados e impressões, que aqui apresentamos com referência à situação atual da educação rural no México, levam a compreender que diferentes iniciativas e esforços do governo federal, com a cooperação dos Estados e dos municípios, e ainda de entidades particulares, nalguns setores, têm contribuído para o desenvolvimento de um vasto plano de 'educação fundamental'. (LOURENÇO FILHO, 1951, p. 68). 
Na última seção do relatório, Lourenço Filho fez uma avaliação geral da educação rural no México em termos de tendências, resultados e perspectivas. Partiu da evolução do pensamento de reforma social para, em seguida, tecer considerações sobre política educacional examinando as prescrições para a educação contidas na Constituição do país. Ele transcreveu parte do documento intitulado "Doutrina da Educação Rural Mexicana" o qual especificava os conceitos e postulados que fundamentavam as políticas educacionais para o setor, as bases teóricas da escola rural mexicana e os objetivos da educação rural expressos em termos de libertação, desenvolvimento e melhoria das condições de vida das populações rurais e, especialmente, dos grupos indígenas. Finalmente ponderou sobre as perspectivas do movimento ressaltando quatro linhas adotadas pela educação rural no México: a) o movimento de educação rural que havia surgido com feição autônoma, mas no momento estava buscando integrar-se no sistema geral de educação do país; b) a intenção políitica inicial de atendimento da população indígena "sob a inspiração dos ideais revolucionários", tendia a se transformar em ação técnica; c) à concepção de que os problemas de vida de cada povoação poderiam ser tratados de per si, sucedia a compreensão mais ampla que intenta soluções 74 regionais; d) a revisão da ideia de que as crianças das povoações rurais deveriam ser preparadas especialmente para as atividades rurais.

Na conclusão do relatório sublinhou mais uma vez a importância da educação rural mexicana como referência para os demais países.

movimento de educação rural, que se desenvolve no México, há mais de trinta anos, oferece abundante material para estudo de questões de sociologia educacional e de política da educação; apresenta também documentação de grande importância para esclarecimento de problemas de administração e organização escolar, e, em particular, dos de organização das técnicas de 'educação fundamental'. (LOURENÇO FILHO, 1951, p. 89).

Esta última concepção sobressaía pela sua abrangência e perspectiva política. A noção de educação fundamental utilizada pela UNESCO asseverava a insuficiência da escola primária para a educação das camadas populares nos países em desenvolvimento e postulava uma ação educativa dirigida simultaneamente a crianças, adolescentes e adultos. Pressupunha a integração de ações educativas formais e informais compreendidas como 
serviço social de grupo, pelo qual, cada comunidade, pelo seu próprio esforço, pudesse vencer os problemas de desenvolvimento econômico e social.

Apresentando uma sensível compreensão sociológica e histórica dos fenômenos educacionais, Lourenço Filho finalizou o texto afirmando que, para compreender o movimento de ensino rural no México, era preciso considerar as raízes históricas e os conflitos de cultura travados nesse país. Além disso, dizia ser preciso compreender "[...] o alto sentido político da assimilação, pela educação, dos grupos 'marginais', existentes nos países subdesenvolvidos." (LOURENÇO FILHO, 1951, p. 91).

Em 9 de maio de 1952, no segundo governo de Getúlio Dornelles Vargas (1951-1954) foi instituída a Campanha Nacional de Educação Rural (CNER) pelo Departamento Nacional de Educação lórgão do Ministério da Educação e Saúde) cuja finalidade era promover a educação de base no meio rural brasileiro. A justificativa para a adoção da educação de base foi diversas vezes reiterada pelos administradores da Campanha, conforme pode ser visto no excerto abaixo:

Essa educação é educação de base porque se destina a proporcionar aos indivíduos e às comunidades o número de conhecimentos teóricos e técnicos indispensáveis a um nível de vida compatível com a atividade humana e com os ideais democráticos, e porque, sem ela, as atividades dos serviços especializados (médicos, sanitários, agrícolas) não seriam plenamente eficazes. (A CAMPANHA NACIONAL..., 1959, p. 26).

Em realidade, como observa Barreiro (2006), a Campanha Nacional de Educação Rural objetivava adequar os camponeses ao novo modelo de desenvolvimento econômico adotado no país de modo a tornar o homem do campo um cidadão, elevando os seus padrões culturais, concebidos como atrasados e inferiores. A CNER valeu-se da noção de educação fundamental como meio de combate ao atraso do homem do campo e utilizou várias modalidades de atuação e organização do trabalho.

As missões rurais, destinadas a promoverem o bem estar das comunidades residentes nas zonas rurais, tiveram um papel importante na CNER. Elas foram concebidas como modalidades de trabalho educacional que articulava a educação às ações de assistência social. De acordo com os dirigentes da CNER em 1959, tratava-se de um "[...] processo móvel que desenvolve 
a técnica de Organização de Comunidade e outras e por meio do qual se promove a Educação de Base junto ao povo, norteando-o para a própria valorização indispensável e dos grupos." (A CAMPANHA NACIONAL..., 1959, p. 279).

A composição dessas missões era formada por médico, agrônomo, assistente social, dentista, veterinário, enfermeira, agente de economia doméstica, técnico de rádio, de cinema, motorista, professores do ensino primário, além de outros especialistas. Segundo Barreiro (1989), o trabalho da Missão Rural dividia-se em três fases: 1. Diagnóstico da região, com o levantamento dos problemas; 2. Planejamento dos trabalhos; 3. Atuação dos técnicos até o ponto onde a comunidade poderia caminhar sozinha. $\bigcirc$ treinamento dos técnicos que constituíam as Missões Rurais era realizado nos EUA. A Missão Rural instalava-se com a preocupação em formar no povo uma mentalidade associativa, de cooperação, despertando dessa forma a consciência do princípio do self-help.

Longe de se constituírem como uma cópia do modelo mexicano, muitas iniciativas de educação rural adotadas no Brasil, como as missões rurais, as granjas escolares, as concepções de educação de base e educação fun-

76 damental, entre outras, adquiriram no país uma especificidade própria em conformidade com as peculiaridades das políticas nacionais para a educação rural e as práticas dos sujeitos envolvidos na CNER. $\bigcirc$ exemplo mexicano foi utilizado como um argumento forte de justificação e de referência de experiências bem sucedidas no exterior. Visto dessa maneira, como estratégia discursiva, o documento de Lourenço Filho cumpriu o papel ordinário das viagens de estudo: observar o ensino em países estrangeiros e fazer circular modelos educacionais.

\section{Considerações finais}

Com o relatório Educação Rural no México, Lourenço Filho ofereceu ao governo e aos educadores brasileiros uma referência exemplar sobre educação rural. Da experiência mexicana profundamente marcada pelos processos de revolução social, o autor extraiu mais os elementos técnico-pedagógicos que convinham à realidade brasileira. Nesse sentido, no texto de Lourenço Filho, a força política da luta dos camponeses pela terra, motivação norteadora da 
pedagogia social mexicana, foi minimizada, enquanto foram enfatizadas as missões rurais, vistas como poderosas estratégias de intervenção na vida dos moradores das regiões rurais.

Dessa maneira, a referência aos princípios revolucionários que mobilizaram e alimentaram a pedagogia social presente nas práticas de educação rural mexicanas foi vista apenas como um componente da trajetória histórica do movimento, pois interessava mais ao autor assinalar a reconfiguração do movimento no contexto democrático.

Como tantos outros autores que buscaram descrever o sistema educacional de outros países, Lourenço Filho também operou com uma imagem invertida, cunhando uma interpretação a partir dos seus próprios valores e das suas concepções sobre a educação rural em conformidade com o que acreditava ser válido para a sociedade brasileira. (SCHRIEWER, 2000).

Ao difundir no Brasil as ideias e práticas de educação vigentes no México, o intelectual brasileiro agia como um mediador da modernização educacional. Ele dava a conhecer ao público brasileiro princípios e concepções educacionais que serviam de orientação para organismos internacionais como a UNESCO e que vinham sendo adotados em outros países.

$\bigcirc$ fato de o México ter sido apontado como sociedade de referência é bastante interessante. Observa-se, neste caso, o deslocamento da sociedade modelo comumente atribuída aos países europeus e aos Estados Unidos para um país americano em desenvolvimento. Sem dúvida, as inovações experimentadas nesse país no campo da educação rural colocavam em questão as possibilidades de os países subdesenvolvidos enfrentarem o atraso e promoverem o desenvolvimento econômico, sociocultural e educacional do campo.

A despeito do lastro político socialista e revolucionário presente em determinados momentos nas políticas educacionais mexicanas, a estratégia de Desenvolvimento de Comunidade, as missões culturais entre outros aspectos, servia a diferentes propósitos ideológicos, fosse às proposições da lgreja, da Organização das Nações Unidas, da Comissão Econômica para a América Latina e o Caribe (CEPAL) ou até mesmo das estratégias de contenção do comunismo promovidas pelos Estados Unidos.

No Brasil, o ideário nacional-desenvolvimentista impelia ações de impacto nas zonas rurais. As concepções de educação de base e de educação fundamental serviram aos propósitos de uma ampla intervenção no 
campo, visando à educação intelectual e moral e a mudanças de hábitos e modos de vida das populações rurais.

Como explica Schriewer (2000, p. 114 ), as referências a exemplos estrangeiros são algo mais que histórias contemporâneas em outros países. "Espera-se que tais referências sirvam como 'lições', que forneçam 'ideias estimulantes' e novos impulsos para a definição de políticas ou para delinear um quadro de referência para a especificação das opções de reforma."

Como também assinalou Gondra, as viagens funcionam como exercício de comparação, "[...] um gesto da razão e uma forma de pensar e tornar o outro pensável." (GONDRA, 2007, p. 67). Como buscamos demonstrar neste texto, Lourenço Filho agiu como um estudioso da educação comparada elaborando um relatório que não somente atestava as suas constatações, impressões e avaliações do que observara no México, mas que se constituía em um estudo comparado.

Mais que unidades de análise, as sociedades e civilizações constituem unidades de referência assim configuradas por argumentos políticos. Significa dizer que a recepção das propostas de educação rural mexicanas no Brasil também pode ser vista como resultado de uma situação histórica específica, a necessidade inadiável do Estado brasileiro de resolver a dramática situação da população rural do país.

Nesse sentido, a referência ao exemplo estrangeiro, no caso, o México, corroborava a intencionalidade de introduzir novas práticas e de adequar a educação brasileira aos padrões em circulação no âmbito internacional. Não se buscava uma cópia ou uma transferência unilateral, mas uma apropriação seletiva na qual o argumento estrangeiro validava as proposições de colorido nacional.

\section{Notas}

1 Este texto compreende resultados parciais de pesquisa em andamento, projeto intitulado "História da Escola Primária Rural no Estado de São Paulo (1931-1968): circulação de referenciais estrangeiros, iniciativas do Poder Público e cultura escolar", financiado pela FAPESP.

2 Há no México inúmeros estudos sobre a história da educação rural nesse país. Ver a título de exemplo, os estudos de Civera (1997, 2007) e López (2007). 


\section{Referências}

A CAMPANHA Nacional de Educação Rural (CNER). Suas origens, sua vida e seus trabalhos desde 1950 ao $1^{\circ}$ semestre de 1959. Revista da Campanha Nacional de Educação Rural, Rio de Janeiro, v. 6, n. 8, 1959.

ÁVILA, Virgínia Pereira da Silva. História do ensino primário rural em São Paulo e Santa Catarina (1921-1952) - uma abordagem comparada. Araraquara, 2013. 217f. Tese (Doutorado em Educação Escolar) - Programa de Pós-Graduação em Educação Escolar, Universidade Estadual Paulista, Araraquara, 2013.

BARREIRO, Iraíde Marques de Freitas. Educação rural capitalista: a contradição entre a educação modernizadora e a educação de classe popular na Campanha Nacional de Educação Rural, 1989. 178f. Dissertação (Mestrado em Educação) - Programa de PósGraduação em Educação, Universidade Estadual de Campinas, Campinas, 1989.

BARREIRO, Iraíde Marques de Freitas. Cidadania e educação rural no Brasil: um estudo sobre a Campanha Nacional de Educação Rural (1952-1963). 1997. 223f. Tese (Doutorado em Educação) - Programa de Pós-Graduação em Educação, Universidade de São Paulo, São Paulo, 1997.

BARREIRO, Iraíde Marques de Freitas. Articulação entre desenvolvimento econômico e educação nos países latinos: Educação rural no Brasil - anos cinquenta. Projeto História, São Paulo, n. 32, p. 123-142, jan. 2006.

BRASIL. Decreto $\mathbf{n}^{\circ} \mathbf{4 . 9 5 8}$, de $\mathbf{1 4}$ de novembro de 1942. Institui o Fundo Nacional do Ensino Primário e dispõe sobre o Convênio Nacional de Ensino Primário. Câmara dos Deputados. Disponível em: <http://www2.camara.leg.br/legin/fed/declei/1940-1949/decreto-lei4958-14-novembro-1942-414976-norma-pe.html>. Acesso em: 16 jan. 2013.

CIVERA, Alicia. Entre o campo y la ciudad: La formación de maestros normalistas rurales y técnicos agrícolas em México, 1921-1945. In: WERLE, Flávia Obino Corrêa. (Org.). Educação rural em perspectiva internacional. Instituições, práticas e formação do professor. ljuí: Editora Unijuí, 2007.

CIVERA, Alicia. Entre surcos y letras. Educación para campesinos em los años treinta. México: El Colegio Mexiquense - Instituto Nacional de Estudios Históricos de la Revolución Mexicana, 1997.

FÁVERO, Maria de Lourdes de Albuquerque; BRITTO, Jader de Medeiros (Org.). Dicionário de Educadores no Brasil: da colônia aos dias atuais. 2 ed. Rio de Janeiro: Editora UFRJ / MEC-Inesp-Comped, 2002. 
GONDRA, José Gonçalves. Exercício de comparação: um normalista da Corte na Europa. In: MIGNOT, Ana Chrystina Venancio; GONDRA, José Gonçalves (Org.). Viagens pedagógicas. São Paulo: Cortez, 2007.

LÓPEZ, Oresta. Representaciones, practicas educativas y mediación cultural de las maestras rurales mexicanas em el contexto posrevolucionario (1920-1940). In: WERLE, Flávia Obino Corrêa (Org.). Educação rural em perspectiva internacional. Instituições, práticas e formação do professor. liuí: Unijuí, 2007.

LOURENCCO FILHO, Manoel Bergstrom. A educação rural no México. Relatório apresentado ao Exmo Sr. Ministro da Educação e Saúde, Dr. Simões Filho. Rio de Janeiro, Instituto Nacional de Pesquisas Educacionais, dez. 1951.

LOURENCCO FILHO, Manoel Bergstrom. A educação rural no México. Revista Brasileira de Estudos Pedagógicos, Rio de Janeiro, v. 17, n. 45, p. 108-198, jan./mar. 1952.

LOURENCCO FILHO, Manoel Bergstrom. Educação comparada. São Paulo: Edições Melhoramentos, 1961. (Obras completas de Lourenço Filho, v. 5).

MIGNOT, Ana Chrystina Venancio; GONDRA, José Gonçalves (Org.). Viagens pedagógicas. São Paulo: Cortez, 2007.

80 MISSÕES Rurais de Educação. A experiência de Itaperuna. Uma tentativa de organização da comunidade. Contribuição para o Serviço Social Rural. Rio de Janeiro: Ministério da Agricultura/Serviço de Informação Agrícola, 1952.

MONARCHA, Carlos. Lourenço Filho. Recife: Fundação Joaquim Nabuco, 20 10. Disponível em: <http://www.dominiopublico.gov.br/download/texto/me4706.pdf>. Acesso em: 12 jan. 2013.

NÓVOA, Antonio. Histoire et comparaison: essais sur l'éducation. Lisboa: Educa, 1998.

NÓVOA, António; YARIV-MASHAL, Tali. Comparative research in education: a mode of governance or a historical journey? Comparative Education, Lisboa, v. 39, n. 4, p. 423438, nov. 2003.

NÓVOA, Antonio. Modelos de análise de educação comparada: o campo e o mapa. In: SOUZA, Donaldo Bello; MARTíNEZ, Silvia Alicia (Org.). Educação comparada: rotas de além-mar. São Paulo: Xamã, 2009.

SCHRIEWER, Jurgen. Estados-modelo e sociedade de referência: externalização em processos de modernização. In: NÓVOA, Antonio; SCHRIEWER, Jurgen. A difusão mundial da escola. Lisboa: Educa, 2000. 
SCHRIEWER, Jurgen. Educación comparada: um programa ante nuevos desafios. In: Formación del discurso en la educación comparada. Barcelona: Ediciones Pomares, 2002.

WARDE, Mirian Jorge. O itinerário de formação de Lourenço Filho por descomparação. Revista Brasileira de História da Educação, Campinas, n. 5, p. 125-167, jan./jun. 2003.

Profa. Dra. Rosa Fátima de Souza Universidade Estadual Paulista "Júlio de Mesquita Filho" | Araraquara Faculdade de Ciências e Letras Universidade Estadual Paulista Programa de Pós-Graduação em Educação | Unesp | Marília Grupo de Estudos e Pesquisas sobre Cultura e Instituições Educacionais | GEPCIE E-mail | rosa@fclar.unesp.br

Recebido 11 mar. 2013 Aceito 7 maio 2013 